\title{
Asthma and beta-blocker prescription: A medico-legal view
}

Regarding the use of beta-blockers in asthmatic patients, the advice in the British National Formulary (BNF) [1] reads as follows: Beta-blockers may precipitate asthma and this effect can be dangerous. Beta-blockers should be avoided in patients with a history of asthma or bronchospasm; if there is no alternative, a cardioselective betablocker may be used with extreme caution under specialist supervision.'

In this issue of the Primary Care Respiratorv Journal, it is argued that astinmatripefiacents are often denied treatritent tar the effective management of (D)- - $x$ stent cardiovas cution dise ase because of the concerns that petalfockers may precipitate fatal bronchospasm [2]. The evidence, say the authors, supports the position that cardioselective beta-blockers, when introduced with care in both community and hospital settings, are safe in patients with mild airways disease and can significantly improve prognosis. The real issue here is not whether beta-blockers are effective in the management of cardiovascular disease, but how cautious doctors should be about prescribing cardioselective beta-blockers in patients with asthma, and, if prescribing, what safeguards are required.

Are general practitioners (GPs) at risk medicolegally if, having prescribed a beta-blocker for an asthmatic patient on consultant recommendation, the patient develops severe asthma, collapses and dies? Given the clear advice in the BNF, a GP prescribing beta-blockers, particularly noncardioselective beta-blockers, is undoubtedly open to criticism, since the BNF is both an accessible and authoritative source of information on the use of drugs. Should the GP decide not to abide by BNF advice, the onus would be on him or her to demonstrate that alternative management was justifiable on the basis of current evidence. The clear guidance in the BNF - that cardio-selective beta-blockers should only be used if there is no alternative, and then with extreme oution under specialist supervision - neanc that in itiating these drugs in ge mial bractice would be hard to justify espedidtity in the event of a severe adverse incident.

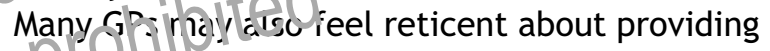
repeat prescriptions to asthmatic patients started on beta-blockers by cardiology specialists. As it is the prescriber who is generally held responsible for consequent ill effects, a commonsense approach would be only to prescribe these drugs when the GP knows the patient is stabilised on them, when they are shown to be beneficial to the patient, and when the consultant and GP agree on required monitoring and follow-up, and the responsibility for it.

Doctors are subject to multiple forms of accountability, including General Medical Council (GMC) inquiries, civil negligence claims, and, in cases of gross negligence, criminal prosecution. In civil claims, the standard of care is determined by reference to a responsible body of medical opinion. Thus, without solid expert evidence that prescribing beta-blockers was in the best interests of asthmatic patients with cardiovascular disease, and that this had been done with the patients's fully informed consent, there is the danger of a finding of negligence [3]. The expectations of the GMC would be broadly similar.

Far more worrying, however, is the prospect of being prosecuted for medical manslaughter. It is 
hard to know just how many doctors are prosecuted for manslaughter but it looks as if there is an upward trend. In 2000, Ferner reported just two cases involving doctors between 1970 and 1989 and 13 cases involving 17 doctors in the years 1990-99 [4]. According to BBC Online, another 11 doctors have been charged since 2000 [5].

But what constitutes medical manslaughter? Case law is set out in the House of Lords' judgment in Adomako's case where Lord Mackay of Clashfern stated; 'The jury will have to consider the extent to which the defendant's conduct departed from the proper standard of care incumbent upon him, involving as it must have done a risk of death to the patient, and was such that it should be judged criminal' [6]. This is an entirely circular approach, with the jury being told that they should convict of a crime if they thought a crime had been committed.

The Court of Appeal were rather more helpful in setting out what a jury might consider with regard to a defendant's behaviour and attitude in determining whether there had been gross negligence; 'if the defendant was indifferent to an obvious risk of injury to health or he actually foresaw the risk but determined nevertheless to run it or the defendant had an appreciation of the risk coupled with an intention to avoid it Dut also coupled with a high degree of negligence in the intended avoidance pr that the detendant had an unintenciorror cidillure to consider a seridus risk which went beyond mere inad'orence in respect of an obvious important matter which the defendant's duty demanded he should have addressed.'

Ferner's series of cases included just one stemming from prescribing beta-blockers to an asthmatic patient [4]. He reported that a 30-year old woman with asthma went to see her GP because she was experiencing palpitations. The
GP prescribed a beta-blocker. She collapsed and died hours after taking the first tablet. The GP subsequently tried to erase all mention of asthma from the patient's record and the practice computer. The doctor was charged with manslaughter and attempting to pervert the course of justice. He was acquitted of the first charge but convicted on the second. In fact, in just six of Ferner's cases were the doctors convicted [4]. In four, the problem arose during general anaesthesia resulting in severe hypoxia and in the other two, opiates had been used in excessive doses.

In summary, the advice set out in the BNF is that prescribing beta-blockers for asthmatic patients should be restricted to specialists who are able to monitor patients closely. It is not the province of GPs without the required expertise or specialist facilities available to them.

\section{References}

[1] British National Formulary, No. 49. March 2005.

[2] Ashrafian H, Violaris AG. Beta-blocker therapy of cardiovascular diseases in patient: with bronchial asthma or COPL: The fro vewpoint. Prim Care Resp J 2005:14 त्र:236-4.

[3]1 Bolam v Friern Hospil al Management Committee [1957] 2 All ER 113. [1] $5=7] 1$ M 582

[4] Fer charges. BMJ 2000;321:1212-6 (11 November).

[5] Doctors 'fear criminal charges'. BBC News online, 3 July 2005.

[6] R v Adomako. [1994] 3 All ER 79.

Gerard Panting* Medical Protection Society 33 Cavendish Square, W1G OPS, London

*Tel.: +44 207399 1336; fax: +44 2073991371

E-mail address: gerard.panting@mps.org.uk

Available online at www.sciencedirect.com

science $\boldsymbol{W}$ Direct. 